\title{
On Creep Failure of Notched Bars
}

\section{Author/Contributor:}

$\mathrm{Ng}$, Lawrence; Zarrabi, Khosrow

\section{Publication details:}

Engineering Failure Analysis

v. 15

pp. $774-786$

1350-6307 (ISSN)

\section{Publication Date:}

2008

\section{Publisher DOI:}

http://dx.doi.org/10.1016/j.engfailanal.2007.06.011

\section{License:}

https://creativecommons.org/licenses/by-nc-nd/3.0/au/

Link to license to see what you are allowed to do with this resource.

Downloaded from http://hdl.handle.net/1959.4/11351 in https:// unsworks.unsw.edu.au on 2023-04-26 


\title{
On Creep Failure of Notched Bars
}

\author{
Ng, $L$ and Zarrabi, $K^{*}$ \\ School of Mechanical and Manufacturing Engineering, University of New South Wales, Sydney, NSW \\ 2052, Australia
}

\begin{abstract}
This paper demonstrates the application of a new multiaxial creep damage model developed by the authors to predict the failure time of components made of service aged $2.25 \% \mathrm{Cr}-1 \% \mathrm{Mo}, 0.5 \% \mathrm{Cr}-0.5 \% \mathrm{Mo}-$ $0.25 \% \mathrm{~V}$ low alloy steels, titanium and nickel-based superalloys. The model accounts for the tertiary creep behaviour and assumes the creep damage is related to the internal energy absorbed by the material. The authors argue that the model is the most appropriate for characterizing gross creep damage from a macroscopic point of view because it takes into accounts both the multiaxial internal deformation and loading. The verification and application of the model are demonstrated by applying it to the Bridgman notched bars for which the experimental data are available. The predicted failure times by the model are compared with the experimental results and those obtained from the reference stress method. The results show that the proposed model is capable of predicting failure times of the components made of the abovementioned materials with an accuracy of $2.2 \%$ or better. Also, it is shown that the model predicts the creep failure times of the components more accurately than the reference stress method.
\end{abstract}

Keywords: Creep Damage; Internal Energy; Creep Life Prediction

\section{Introduction}

Because of economical and environmental factors, there is a general trend towards improved efficiencies in various industries particularly in power and chemical plants. In such industries, there are many components that operate within the creep range and the creep damage is one of the main sources of failure of such components. Therefore, there is a need for the generation of pragmatic models in predicting whether the components operating in the creep range will sustain the life required of them. Prediction of the creep life of such engineering components with sufficient accuracy would produce many benefits including less damage to the environment and significant economic gains for industry. This may also help by diverting failed industrial components away from landfills, which would have significant environmental benefits. Also, a more accurate life prediction for components employed in electricity generation might allow for the operation of equipments at higher temperatures and thus would reduce the emission of harmful gases into the atmosphere. To predict creep lives, one of the essential ingredients is a creep damage model.

Although the creep damage models that are based on microscopic behaviour of materials have increased our understanding and knowledge, they have proved to be too complex for practical engineering applications. The existing creep damage models that are based on a macroscopic approach include: the Robinson time/strain fraction method [1], the reference stress approach [2], the Kachanov-Rabotnov continuum damage

*Corresponding author. Tel.: +61293855693; fax.: +61296631222
E-mail address: k.zarrabi@unsw.edu.au 
mechanics, KR-CDM [3,4] and the Omega model [5]. The Robinson time/strain fraction model assumes creep failure occurs when:

$\sum_{i=1}^{n} \frac{\Delta t_{i}\left(\sigma_{r}\right)}{t_{r i}\left(\sigma_{r}\right)}=1$

or:

$\sum_{i=1}^{n} \frac{\Delta \varepsilon_{i}\left(\sigma_{r}\right)}{\varepsilon_{r i}\left(\sigma_{r}\right)}=1$

where $\Delta t_{i}\left(\sigma_{r}\right)$ and $\Delta \varepsilon_{i}\left(\sigma_{r}\right)$ are sufficiently small time intervals and total strain increments respectively during which the rupture stress, $\sigma_{r}$, is taken to be constant, $t_{r i}\left(\sigma_{r}\right)$ and $\varepsilon_{r i}\left(\sigma_{r}\right)$ are the time and total stain failures at $\mathrm{i}^{\text {th }}$ time interval. The abovementioned variables are functions of $\sigma_{r}$ which is the stress component that is responsible for creep failure. $\sigma_{r}$ is taken to be a mix of the major principal stress ( $\sigma_{1}$, causing creep cavitation) and the equivalent stress ( $\sigma_{e}$, causing dislocation glide or grain boundary sliding), usually as [6]:

$\sigma_{r}=\alpha \sigma_{1}+(1-\alpha) \sigma_{e}$

where $\alpha$ is a material parameter whose value is usually not known a priori and its evaluation is time-consuming and expensive producing a significant limitation for applying this model to practical engineering problems. To circumvent this problem, in practice, it is often assumed that either $\alpha=0$ or $\alpha=1$ but this can increase error in the final results (see Section 3).

The reference stress approach is based on the notion that there is a unique timeinvariant stress level known as the reference stress ( $\left.\sigma_{\text {ref }}\right)$ within a component that can be used to characterize its creep behaviour $[7,8]$. Combining this concept with the idea expressed by equation (3) gives:

$\sigma_{\text {ref }}=\beta \sigma_{\text {ref } 1}+(1-\beta) \sigma_{\text {ref } e}$

where $\sigma_{r e f 1}$ is the reference major principal stress, $\sigma_{r e f} e$ is the reference equivalent stress (see Section 4) and $\beta$ similar to $\alpha$ is a material parameter whose value is usually not known a priori and therefore, in practice, it is often assumed that either $\beta=0$ or $\beta=1$ but this can again increase error in the final results (see Section 4).

KR-CDM is based on two coupled equations that combine the creep constitutive behaviour with damage. There are few such equations typified by: 


$$
\begin{aligned}
& \frac{d \varepsilon_{i j}^{c}}{d t}=\frac{3}{2} A \frac{\left(\sigma_{e}\right)^{(n-1)} S_{i j}}{(1-D)^{n}} t^{m} \\
& \frac{d D}{d t}=M \frac{\left(\sigma_{r}\right)^{x}}{(1+\Phi)(1-D)^{\Phi}} t^{m}
\end{aligned}
$$

where $A, m, n, M, \Phi$ and $x$ are material constants that depend on temperature, $S_{i j}$ are the deviatoric stress components, $t$ is time, $\varepsilon_{i j}^{C}$ are creep strain components and $D$ represents the creep damage. It is assumed that when $t=0$ then $D=0$, and when $t=t_{r}$ then $D=1$ where $t_{r}$ is time to rupture. However, by and large, $D \neq 1$ at rupture. Another problem is that the pertinent material constants are not readily available. Furthermore, as explained before, $\sigma_{r}$ is not known. To date, KR-CDM has not been incorporated in most commercial finite element computer codes and therefore its application may not be practical where the practicing engineer has limited time to carry out the failure analysis.

The Omega model is another method of assessing creep lives of the components. It was developed by the Materials Properties Council and assumes that: the life fraction used, strain, and strain rates all depend on a material creep damage parameter coined "Omega". To obtain the Omega parameter requires various material data and other parameters that are not readily available and to date this method has not been generally adopted. Also, the Omega model cannot be used to assess lifetimes of thermally degrading materials because the creep damage mechanism violates the physics underpinning the basis of $\Omega$ methodology.

In summary, the major disadvantages of the current creep life/damage models are: (a) they may be too complex for practical applications, (b) the pertinent material data may not be readily available and (c) the predicted lives may not be sufficiently accurate. The authors have previously proposed a model that overcomes the above-mentioned problems and they have verified it for pressure vessels and tubes made of $2.25 \% \mathrm{Cr} 1 \% \mathrm{Mo}$ steel [9]. For the sake of completeness a brief description of this model follows and then its verification and application further investigated for predicting the failure of notched bars made of four different alloys. Note that notches are a convenient means of creating a triaxial state of stress/strain.

\section{Nomenclature}

$\begin{array}{ll}\alpha, \beta, A, m, n & : \text { Material parameter } \\ M, \Phi, \chi & : \text { Continuum damage material constants } \\ \sigma & : \text { Stress } \\ \sigma_{i j} & : \text { Stress tensor } \\ \sigma_{\text {ref }} & : \text { Equivalent reference stress }\end{array}$




\begin{tabular}{|c|c|}
\hline$\sigma_{r e f_{1}}$ & : Principle reference stress \\
\hline$S_{i j}$ & : Deviatoric stress tensor \\
\hline$\varepsilon_{i j}$ & : Strain tensor \\
\hline$\varepsilon_{i j}^{e}$ & : Elastic strain tensor \\
\hline$\varepsilon_{i j}^{c}$ & : Creep strain tensor \\
\hline$\varepsilon_{i j}^{c}$ & : Creep strain rate \\
\hline$\varepsilon_{i j}^{e}$ & : Elastic strain rate \\
\hline$B, n$ & : Creep material property \\
\hline$D$ & : Creep damage parameter \\
\hline$F_{1 \ldots n}$ & : Nominal forces \\
\hline$t$ & : Time \\
\hline$t^{\prime} r$ & : Time to rupture \\
\hline$W$ & : Internal energy parameter \\
\hline$d \dot{W}$ & : Internal energy density rate \\
\hline$d W^{e}$ & : Elastic internal energy density rate \\
\hline$d \dot{W}^{c}$ & : Creep internal energy density rate \\
\hline$\dot{W}_{t}$ & : Thermal internal energy density rate \\
\hline
\end{tabular}

\section{Creep Damage Model Based on Exhaustion of Internal Energy}

The model proposes that the creep damage induced in the material is proportional to the total energy that is input to the material. Although the proposed model has the potential to be extended for application in cracked components, the present investigation concentrates on defect-free components. Let the material be homogenous, isotropic and creep ductile. The present model allows for the material to undergo elastic-creep deformation and assumes that the dominant damage mechanism is creep and at the point of failure the component fails by excessive creep deformation and/or creep rupture. Consider a component that is subjected to several loads and that taken together, constitute a set: $\{F\}=\left\{F_{1}, F_{2}, \ldots F_{n}\right\}$. These loads are increased in their respective magnitudes from 
zero to their operational levels over a relatively short period of time so that it can be assumed that at $t=0$ they instantaneously cause elastic deformation only. Having reached their respective operational levels, the loads and material temperature are taken to be constant until the point of failure. As time progresses, the material undergoes creep deformation. In the following the superscript ' $e$ ' refers to elastic and ' $c$ ' refers to creep. At time $t$ the rate of the total internal energy per unit of volume (i.e., the internal energy density rate), $d \dot{W}$ is the sum of the rates of: elastic internal energy per unit of volume, $d W^{e}$ and creep internal energy per unit of volume, $d W^{c}$ :

$d \dot{W}=d \dot{W} \dot{W}^{e}+d \dot{W}$

This may be expressed in terms of stress $\left(\sigma_{i j}\right)$ and strain rate $\left(\varepsilon_{i j}^{k}\right)$ components as:

$\dot{d W}=\sigma_{i j}\left(\dot{\varepsilon}_{i j}^{e}+\dot{\varepsilon}_{i j}^{c}\right)+\dot{W}_{t}$

where $\dot{W}_{t}$ is the rate of the internal (thermal) energy in the absence of stress per unit | volume. The average total internal energy per unit of volume, i.e., at a point ${ }_{2}$ can be calculated by integrating equation (9) with respect to time:

$W=\iint\left[\sigma_{i j}\left(\varepsilon_{i j}^{e}+\varepsilon_{i j}^{c}\right)\right] d t+\iint \dot{W}_{t} d t$

Note that the second term in equation (10), i.e., $W_{t}=\iint \dot{W}_{t} d t$ is the average input thermal energy per unit of volume (at a point) and it accounts for the microstructural damage in the absence of stress. It may be calculated analytically for simple cases or numerically using the finite element method for more complex cases. Note also that at the normal operational stress levels, the microstructural damage is also and indirectly accounted for by the pertinent material parameters. Therefore, one may postulate that under normal operation where stresses are significant, then first term (i.e., the strain energy) in equation (10) is dominantly responsible for the damage in the material. On the other hand as stresses are reduced and approach zero then $W_{t}$ will be dominantly responsible for the damage. Previous work by the authors [10] for steady-state creep behaviour has shown that this postulation is correct, see also the Section 3. To obtain $W$ using equation (10), one needs first to compute the stress and strain fields up to the rupture time as a function of time. Again, for simple problems this may be achieved analytically and for more complex cases a numerical method such as the finite element method may be employed. In determining the stress and stain fields as functions of time, the creep constitutive relationships up to the point of rupture must be used. These data are essential ingredients of any creep analysis and are obtained from uniaxial creep tests. If 
no direct material data are available, published generic data may be utilised, with appropriate sensitivity analyses to cover the uncertainties. As it becomes clear later in this section, the model requires the inclusion of the uniaxial creep tertiary. If the uniaxial tertiary creep data are not available, one can include the effect of the tertiary creep by suddenly increasing the creep strains near the uniaxial time-to-rupture (see next section). Note that in a creep finite element analysis, small time increments might be needed as the analysis approaches the tertiary region and near the component rupture time. Also, in the finite element method, there will be a time, at which a solution might not converge, even for small time increments. This situation then indicates that the creep failure point of the component has been reached.

As described above the proposed model is based on exhaustion of the internal energy absorbed by the material, which is a continuum damage concept and characterises the creep response of the component by considering a plot of the total internal energy per unit of volume at the most critically loaded point versus time as schematically depicted in Fig. 1.

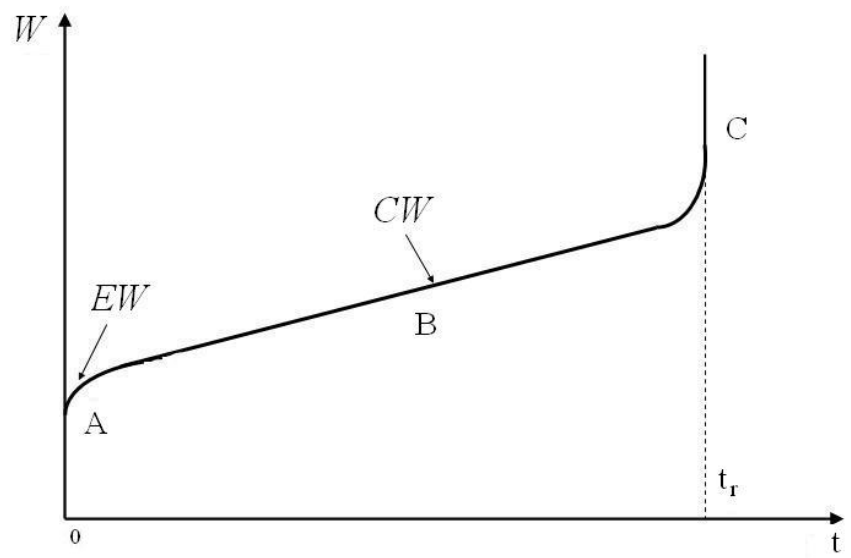

Fig 1. A schematic presentation of total internal energy per unit volume versus time at most critically loaded point

Referring to Fig. 1, at $t=0$, the creep internal energy per unit volume, i.e., CW, is zero and the total internal energy per unit volume is equal to the elastic internal energy per unit of volume $(\mathrm{EW})$. As time progresses, the creep damage increases and hence the curve A-B-C in Fig. 1. The exact shape of the curve A-B-C in Fig. 1 that accounts for $\mathrm{CW}$ is determined by the creep constitutive equations and the way that the tertiary region is modelled, the component geometry, boundary conditions and the loading. If the uniaxial steady-state creep (say, Norton law) is solely available, the model assumes that the uniaxial creep strains vary linearly with time until the point of failure at which the | creep strains suddenly, and over a relatively short period of time ${ }_{2}$ approach infinity. In this case, a sharp transition may occur at the point of failure. Again this situation is identified in a numerical solution by divergence of the solution. In general, the model proposes that as the failure point is approached, equal increments of time cause increasingly greater amounts of $\mathrm{CW}$. At the point of failure, the curve A-B-C in Fig. 1 becomes almost vertical where $d W / d t \rightarrow \infty$ (or $d t / d W \rightarrow 0$ ) and unlimited creep flow occurs. This means that at $t=t_{r}$, the component experiences excessive creep 
deformation and failure (rupture) occurs. To obtain the creep life $\left(t_{r}\right)$, the model proposes to calculate and plot the total internal energy per unit of volume at the most critically loaded point against time. As mentioned above, this may be achieved analytically for relatively simple problems or numerically using the finite element method for more complex problems. Referring to Fig. $1, t_{r}$ is determined by constructing the straight-line tangent to the creep region where it is (nearly) vertical (curve BC in Fig. 1) and finding its intersection with the abscissa representing time or by divergence of the numerical solution near $t_{r}$. Note that Fig. 1 establishes if $t_{r}$ has been reached, or if smaller time increments are required, when the finite element method is employed. The application of the proposed model to a number of notched bars will be described below.

\section{Verification and Application}

Hyde, T, et al, [11,12,13] and Kwon et al [14] performed creep tests using a number of notched bars. To demonstrate the application of the damage model described in Section 2 , it is applied to these notched bars and the predicted creep lives are compared with the experimental lives as described below. The notched bars have identical nominal dimensions and are made from four different materials, viz.: two service aged low alloy steel of $2.25 \% \mathrm{Cr} 1 \mathrm{Mo}$ and $0.5 \% \mathrm{Cr}-0.5 \% \mathrm{Mo}-0.25 \% \mathrm{~V}$; a titanium alloy and a nickel-based superalloy. The bar made of 2.25\%Cr1Mo steel had double Bridgman notches (Fig. 2) and all other bars had a single Bridgman notch (Fig. 3). In what follows MSC.MARC finite element code [15] was employed using 6-node triangular axisymmetric elements for each finite element analysis. In the case of single notched bars, because of symmetry, half of the length of the bar is modelled for the finite element analysis. In the case of the double notched bar, it is assumed that the notches are sufficiently apart so that its finite element mesh will not differ from that used for the single notched bar. This assumption is proved to be correct as the stress/strain fields are localised in the vicinity of each notch. A typical finite element mesh is shown in Fig. 4.

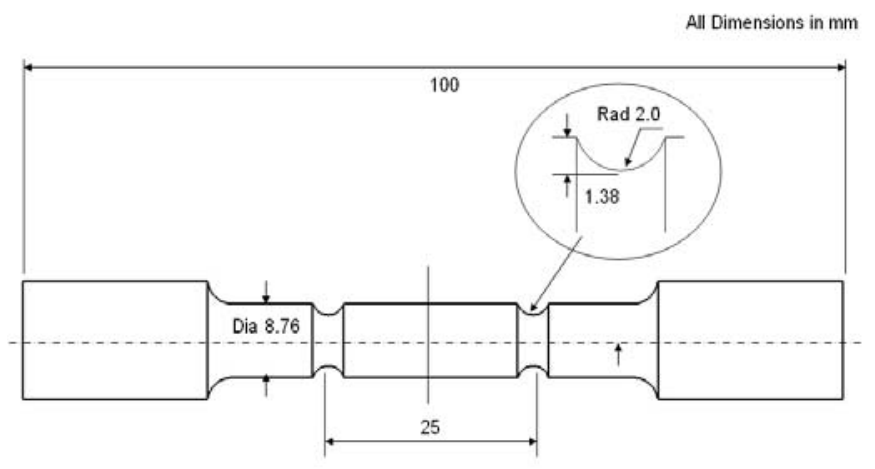

2. Bar with double Bridgman notches made of $2.25 \%$ Cr1Mo steel 


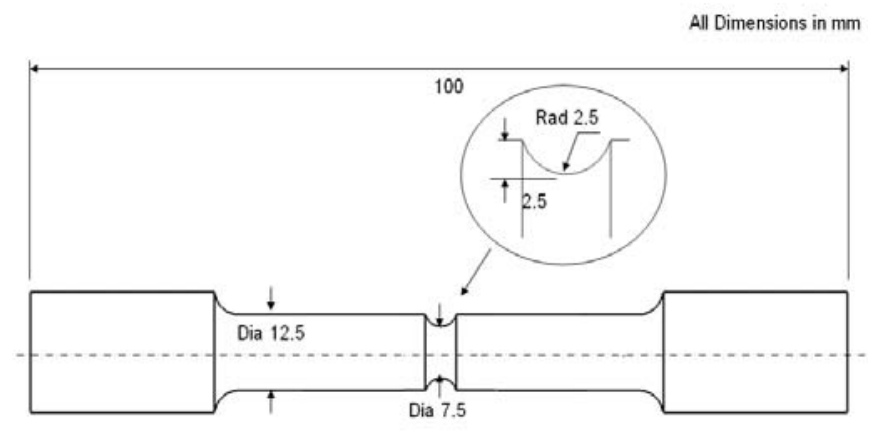

3. Bar with the single Bridgman notch made of either $0.5 \% \mathrm{Cr}-0.5 \% \mathrm{Mo}-0.25 \% \mathrm{~V}$ or titanium or nickelbased superalloy

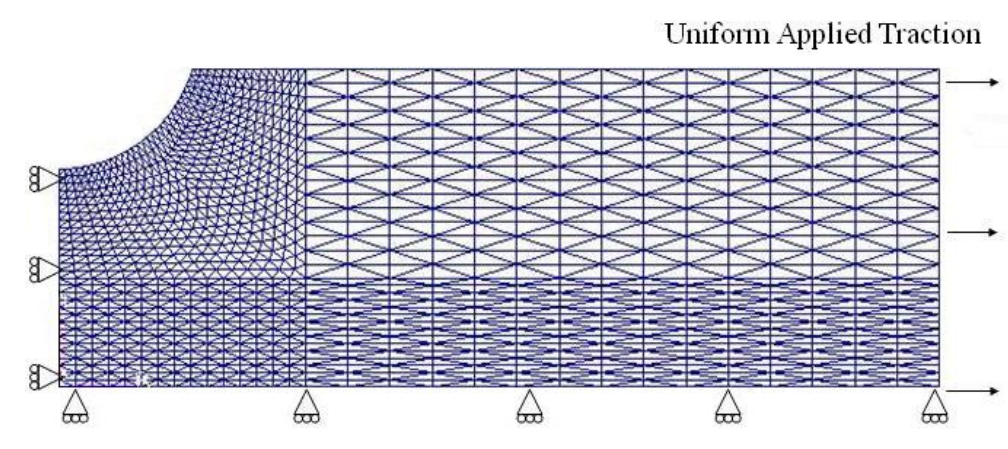

Fig 4. A typical finite element mesh

For each bar, the tests assume the uniaxial creep constitutive equation in form of the steady-state Norton law, i.e., $\varepsilon^{c}=B \sigma^{n}$ where $B$ is the creep coefficient and $n$ is the creep stress exponent. To include the tertiary creep behaviour, the authors modified this equation to:

$\varepsilon^{c}=B \sigma^{n}\left(1+e^{t-t_{r}^{\prime}}\right)$

where $t_{r}^{\prime}$ is the uniaxial rupture time. The first term on the right-hand side of equation (11) represents the steady-state behaviour and the second term the tertiary behaviour.

\subsection{Notched Bar Made of 2.25\%Cr-1\%Mo Steel}

The bar is subjected to a uniform axial traction of $80.22 \mathrm{MPa}$ and a uniform temperature of $550^{\circ} \mathrm{C}$. The modulus of elasticity at the test temperature is $0.157 \times 10^{6} \mathrm{MPa}$. Also, $n=9.0$ and $B=6.408 \times 10^{-14}$ where these values when used in equation (11) result in time in hours and stress in $M P a$. The uniaxial rupture data are described by [14]: 
$\sigma=\left[\frac{t_{r}^{\prime}}{2.1830 \times 10^{20}}\right]^{-1 / 7.9}$

where $t_{r}^{\prime}$, is in hours and $\sigma$ is in $M P a$. Combining equations (11) and (12) will give:

$\varepsilon^{c}=B \sigma^{n}\left[1+e^{t-2.183 \times 10^{20} \sigma^{-7.9}}\right]$

The tests reported in [14] resulted in an average experimental life of 3,899 hours. The finite element mesh of this bar consisted of 2250 six-node axisymmetric triangular elements. The computed axial and equivalent von Mises stresses versus radial distance for various time points are plotted in Figs. 5 and 6 respectively. Using the finite element results and equation (10), and noting that at the applied traction the second term in equation (10) vanishes, the total strain energy per unit volume at the notch root (the most critically loaded point in the bar) is computed and plotted versus time in Fig. 7.

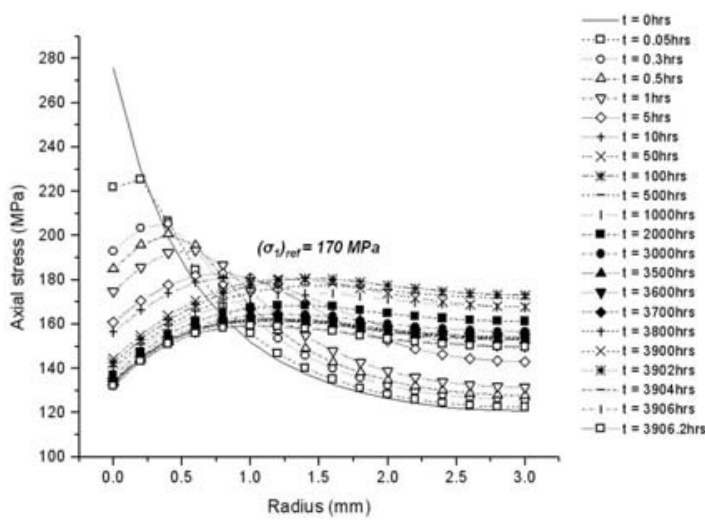

5. Axial stress versus radial distance at various time points for the Bridgman bar made of $2.25 \% \mathrm{Cr} 1 \% \mathrm{~V}$ steel

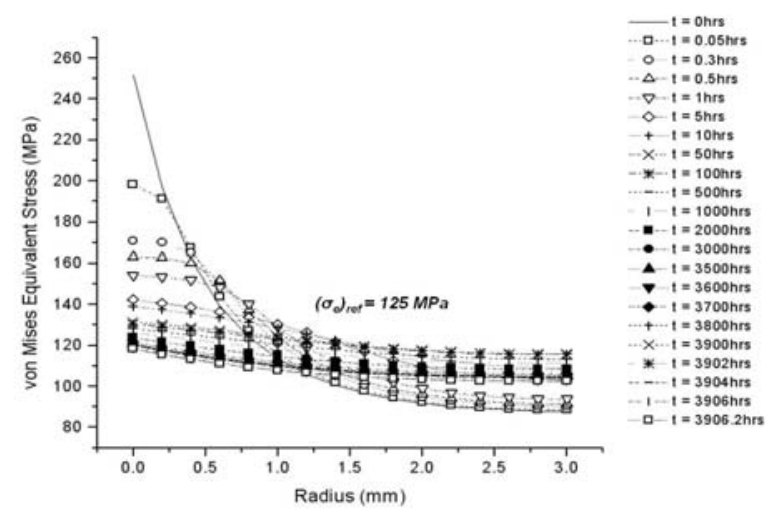

6. von Mises equivalent stress versus radial distance at various time points for the Bridgman bar made of $2.25 \% \mathrm{Cr} 1 \% \mathrm{~V}$ steel 
Referring to Fig. 7, the rupture time is obtained by constructing the straight-line tangent to the creep region where it is (nearly) vertical. This gave the rupture time for the bar as $t_{r}=3,906$ hours (see also Table 1).

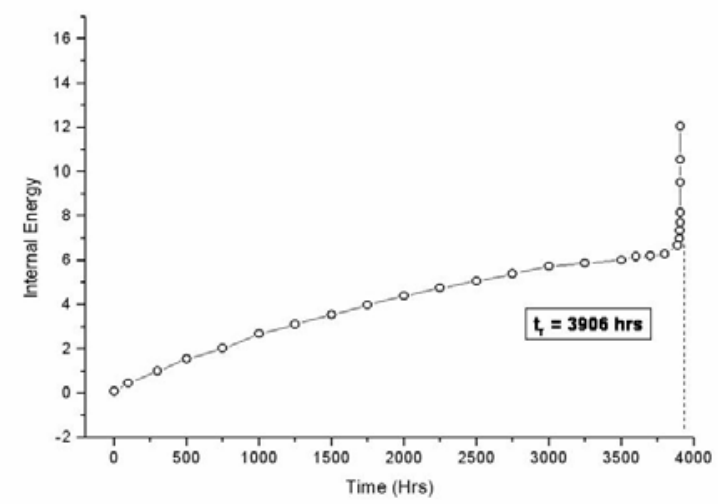

7. The total strain energy per unit of volume at the notch root versus time for the Bridgman bar made of $2.25 \% \mathrm{Cr} 1 \% \mathrm{~V}$ steel

\subsection{Notched Bar Made of 0.5\%Cr0.5\%Mo0.25\%V Steel}

The bar is subjected to a uniform axial traction of $25.2 \mathrm{MPa}$ and a uniform temperature of $640^{\circ} \mathrm{C}$. Its modulus of elasticity at the test temperature is $0.150 \times 10^{6} \mathrm{MPa}$. Also, $n=6.108$ and $B=6.599 \times 10^{-16}$ where these values result in time in hours and stress in $M P a$. The tests described in [11] give the average experimental life of 1,520 hours. The uniaxial creep rupture data are described by:

$$
\sigma=-21.529 \log t_{r}^{\prime}+124.95
$$

Combining equations (11) and (14) will give:

$\dot{\varepsilon}^{c}=B \sigma^{n}\left[1+e^{t-10^{\left(\frac{\sigma-124.95}{-21.529}\right)}}\right]$

Similar analysis to that described in Section 3.1 are carried out here and the finite element mesh consisted of 2550 six-node axisymmetric triangular elements. The computed axial von Mises equivalent stresses and the total strain energy per unit of volume at the notch root are depicted in Figs. 8, 9 and 10 respectively from which the life of the bar is determined as 1,507 hours, see also Table 1. 


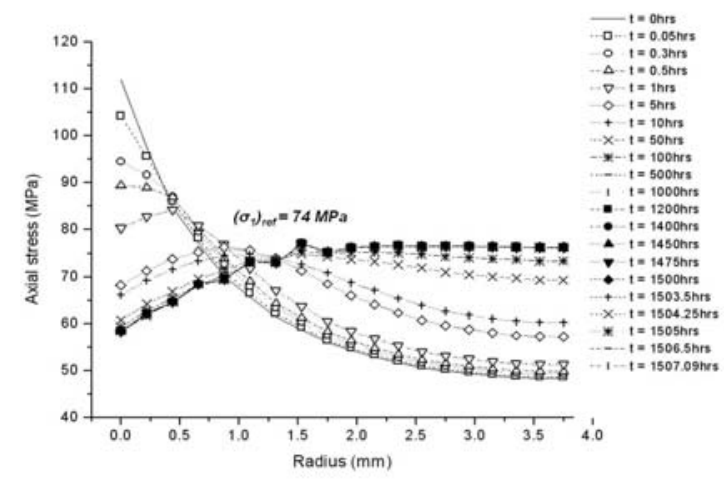

8. Axial stress versus radial distance at various time points for the Bridgman bar made of $0.5 \% \mathrm{Cr} 0.5 \% \mathrm{Mo} 0.25 \% \mathrm{~V}$ steel

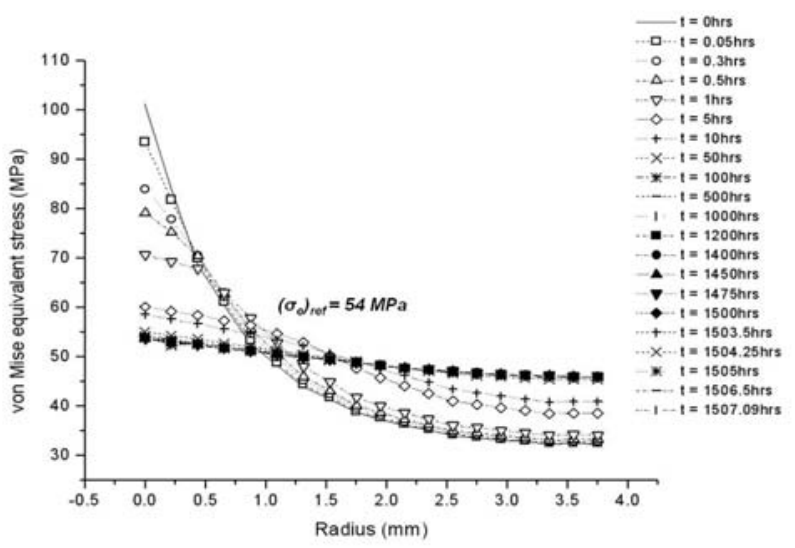

9. - von Mises equivalent stress versus radial distance at various time points for the Bridgman bar made of $0.5 \% \mathrm{Cr} 0.5 \% \mathrm{Mo} 0.25 \% \mathrm{~V}$ steel

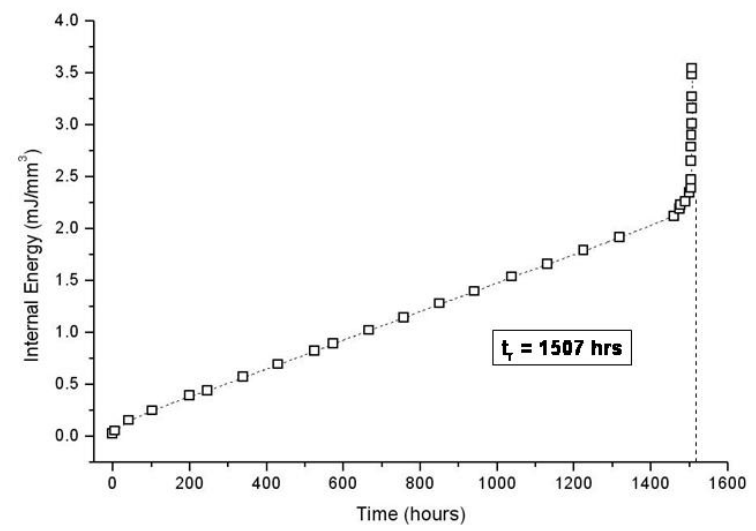

10. The total strain energy per unit of volume at the notch root versus time for the Bridgman bar made of $0.5 \% \mathrm{Cr} 0.5 \% \mathrm{Mo} 0.25 \% \mathrm{~V}$ steel 


\subsection{Notched Bar (Titanium)}

The bar is subjected to a uniform axial traction of $136.8 \mathrm{MPa}$ and a_uniform temperature of $650^{\circ} \mathrm{C}$. Its modulus of elasticity at the test temperature is $0.0895 \times 10^{6} \mathrm{MPa}$. Also, $n=5.911$ and $B=5.911 \times 10^{-16}$ where these values give time in hours and stress in $\mathrm{MPa}$. The tests described in [13] give the average experimental life of 92 hours. The uniaxial creep rupture data with $t_{r}^{\prime}$ in hours and $\sigma$ in MPa are described by [12]:

$\sigma=-116.83 \log t_{r}^{\prime}+599.85$

Combining equations (11) and (16) will give:

$$
\varepsilon^{c}=B \sigma^{n}\left[1+e^{t-10}\left(\frac{\sigma-599.85}{-116.83}\right)\right]
$$

Similar analyses to those described in Sections 3.1 and 3.2 are carried out here. The computed axial and von Mises equivalent stresses and the total strain energy per unit of volume at the notch root are depicted in Figs. 11, 12 and 13 respectively from which the life of the bar is determined as 90 hour, see also Table 1 .

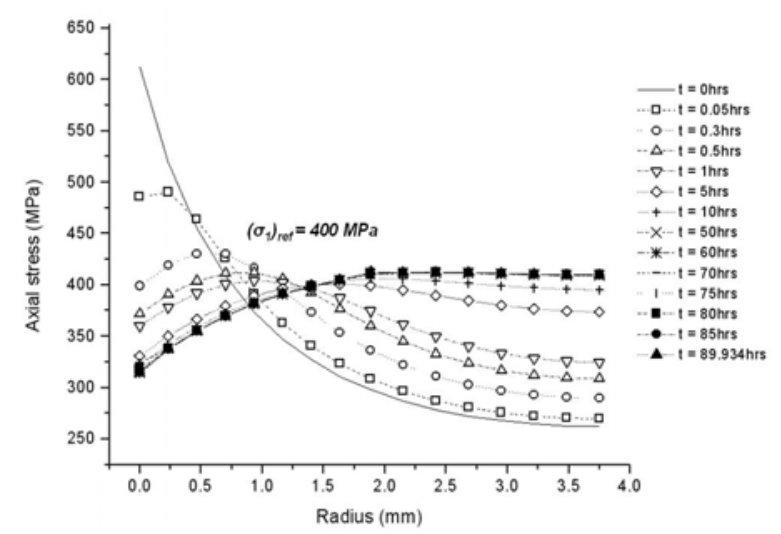

11. Axial stress versus radial distance at various time points for the Bridgman bar made of Titanium-based alloy 


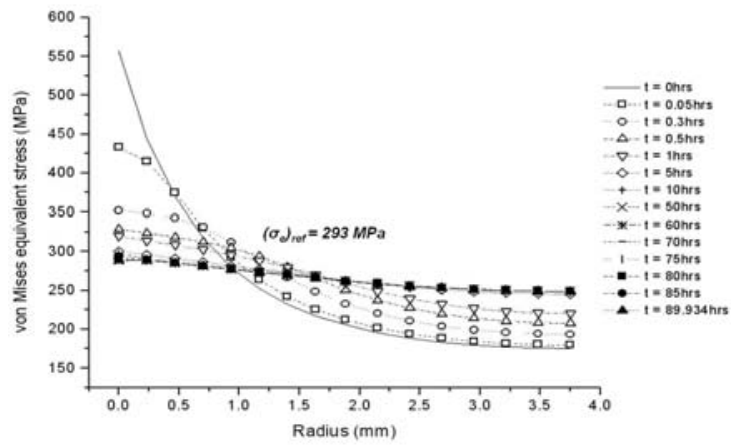

12. von Mises equivalent stress versus radial distance at various time points for the Bridgman bar made of Titanium-based alloy

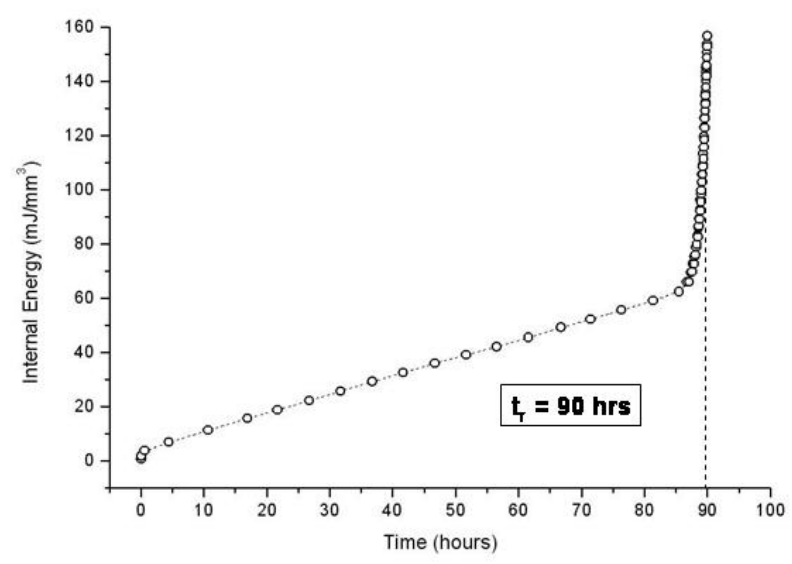

13. The total strain energy per unit of volume at the notch root versus time for the Bridgman bar made of Titanium-based alloy

\subsection{Notched Bar (Nickel-based Superalloy)}

The bar is subjected to a uniform axial traction of $220 \mathrm{MPa}$ and a_uniform temperature of $650^{\circ} \mathrm{C}$. Its modulus of elasticity at the test temperature is $0.178 \times 10^{6} \mathrm{MPa}$. Also, $n=10.647$ and $B=9.226 \times 10^{-34}$ where these values give time in hours and stress in $M P a$. The tests described in [12] give the average experimental life of 2,010 hours. The uniaxial creep data relating time-to-rupture ( $t_{r}^{\prime}$, in hours) to stress ( $\sigma$, in $\left.M P a\right)$ are [13]:

$\sigma=-126.37 \log t_{r}^{\prime}+867.68$

Combining equations (11) and (18) will give: 
$\varepsilon^{c}=B \sigma^{n}\left[1+e^{\left.t-10^{\left(\frac{\sigma-867.68}{-126.37}\right)}\right]}\right.$

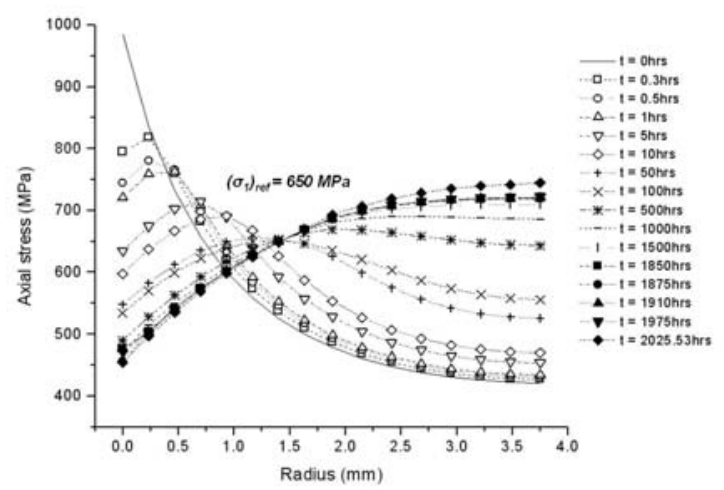

14. Axial stress versus radial distance at various time points for the Bridgman bar made of Nickel-based superalloy

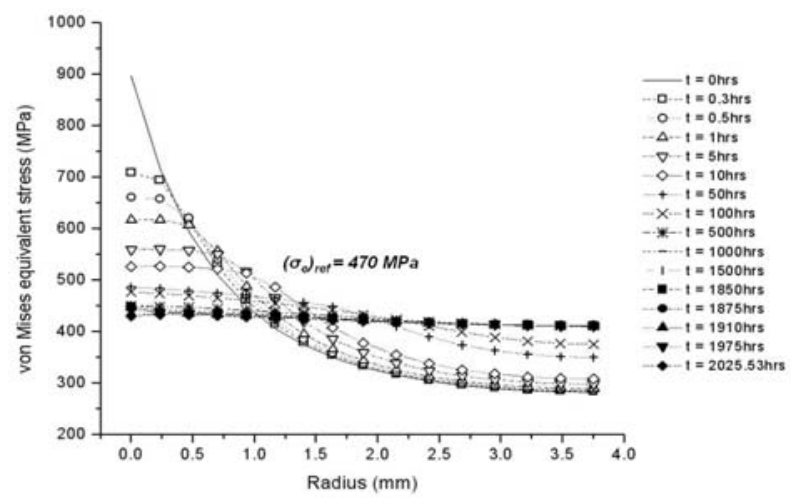

15. von Mises equivalent stress versus radial distance at various time points for the Bridgman bar made of Nickel-based superalloy

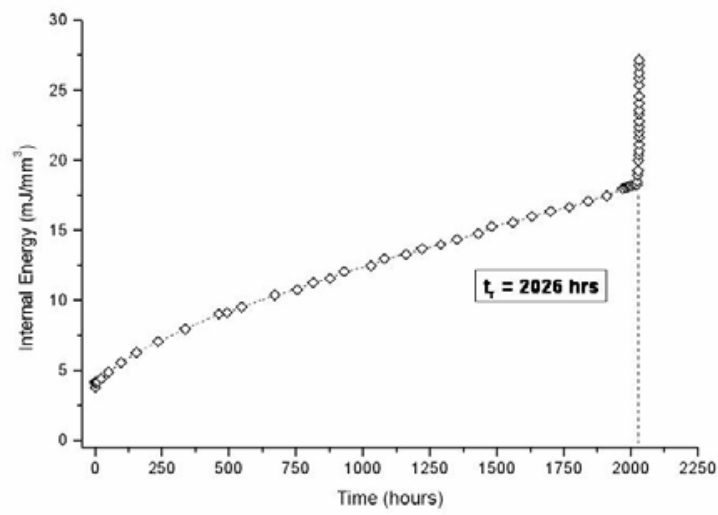

16. The total strain energy per unit of volume at the notch root versus time for the Bridgman bar made of Nickel-based superalloy 
Similar analyses to those described in Sections 3.1, 3.2 and 3.3 are carried out here. The computed axial stress, von Mises equivalent stress and total strain energy per unit volume at the notch root are depicted in Figs. 14, 15 and 16 respectively from which the life of the bar is predicted as 2026 hours, see also Table 1.

\section{Results and discussion}

From the computed major principal and von Mises equivalent stresses versus radius at various time points, it is apparent that initially the elastic stresses are highest at the notch root. As might be expected, these stresses redistribute with time causing a more uniform stress distribution across the notched section.

Using the finite element results and equation (4) the reference stress for each bar is calculated. In doing so it is assumed that either $\beta=0$ or $\beta=1$. As explained before the true value of $\beta$ is usually unknown. This is because to determine the true value of $\beta$ one requires knowing the life of the bar but determination of the life is the objective of the analysis. Having calculated the reference stress for each bar, it is combined with the respective uniaxial creep rupture data to obtain the life of each bar using the reference stress method.

Referring to the results summarized in Table 1, it is apparent that the proposed creep damage model is able to predict creep lives accurately with the maximum error being 2.2\% observed for the notched bar made of titanium. Note that due to the_complexity involved, and the scatter of the results from the high temperature testing, the $2.2 \%$ difference between the experimental and predicted lives is negligible. On the other hand, the errors involved in the reference stress method vary from $-52.2 \%$ to $97.4 \%$ indicating this method may be non-conservative and relatively inaccurate. This is due to: (i) scatter in determining the skeletal point from the plot of the stress versus radial distance in which the stresses at various time steps may not intersect at a single point and (ii) uncertainty about $\beta$.

\section{Conclusions and Recommendations}

A multiaxial and pragmatic creep damage model developed by the authors has been outlined. Its application to various notched bars made of various alloys at different temperatures has been described. It is shown that the model is capable of predicting creep lives with negligible errors, i.e., for the range of bars considered the maximum error is $2.2 \%$.

The model has several advantages when compared with other continuum creep damage models. The model is based on the exhaustion of the total internal energy in the highly stressed/strained zone in the material and therefore it is a true multiaxial model taking into account the contributions from all the stress/strain components. This is a measure of total deformation as well as internal loading in the component and therefore it should be the most appropriate way of characterising gross creep damage. In practical terms, the model does not require quantities such as rupture stress, the damage parameter and some material parameters that are cumbersome and costly to determine and/or employ in practice. Therefore, it should be more practical and should result in more accurate predictions for the creep life of components. In addition, the proposed model is relatively simple to employ and can be used in conjunction with any commercial finite element code with creep analysis capabilities 
Table 1

Comparison of predicted and experimental creep lives of the notched bars

\begin{tabular}{|c|c|c|c|c|c|c|c|c|}
\hline \multirow{3}{*}{$\begin{array}{c}\text { Life } \\
\text { Prediction } \\
\text { Methods }\end{array}$} & \multicolumn{8}{|c|}{ Notched Bars } \\
\hline & \multicolumn{2}{|c|}{$\begin{array}{c}2.25 \% \mathrm{Cr} 1 \% \mathrm{Mo} \\
\text { Steel }\end{array}$} & \multicolumn{2}{|c|}{$\begin{array}{c}0.5 \% \text { Cr0.5\%Mo } \\
\text { 0.25\%V } \\
\text { Steel } \\
\end{array}$} & \multicolumn{2}{|c|}{ Titanium } & \multicolumn{2}{|c|}{$\begin{array}{c}\text { Nickel-based } \\
\text { Superalloy }\end{array}$} \\
\hline & $\begin{array}{l}\text { Life } \\
\text { (hours) }\end{array}$ & $\begin{array}{c}\text { Error } \\
(\%)\end{array}$ & $\begin{array}{c}\text { Life } \\
\text { (hours) }\end{array}$ & $\begin{array}{c}\text { Error } \\
(\%)\end{array}$ & $\begin{array}{c}\text { Life } \\
\text { (hours) }\end{array}$ & $\begin{array}{c}\text { Error } \\
(\%)\end{array}$ & $\begin{array}{l}\text { Life } \\
\text { (hours) }\end{array}$ & $\begin{array}{l}\text { Error } \\
(\%)\end{array}$ \\
\hline Experimental & 3,899 & 0 & 1,520 & 0 & 92 & 0 & 2,010 & 0 \\
\hline $\begin{array}{l}\text { Creep Damage } \\
\text { Model }\end{array}$ & 3,906 & -0.2 & 1,507 & 0.9 & 90 & 2.2 & 2,026 & -0.8 \\
\hline $\begin{array}{l}\text { Reference } \\
\text { Stress Method } \\
\text { when } \\
\beta=0\end{array}$ & 5,936 & -52.2 & 1975 & -29.9 & 423 & 359.8 & 1403 & 30.2 \\
\hline $\begin{array}{l}\text { Reference } \\
\text { Stress Method } \\
\text { when } \\
\beta=1\end{array}$ & 523 & 86.6 & 233 & 84.7 & 51 & 44.6 & 53 & 97.4 \\
\hline
\end{tabular}

\section{References}

[1] Robinson E L, Transaction of ASME; 74:1952. p. 777.

[2] Penny, R K, Marriot, D L, Design for Creep: London, UK: Chapman \& Hall; 1995.

[3] Kachanov L M, Izv Akad Nauk, SSSR: Ser Fiz; 8:1958. p. 26-31.

[4] Rabotnov Y N, Proc XII IUTAM Congress; Stamford, CN, eds: Hetenyi \& Vincent, Springer; 1969. p.137.

[5] Prager M, The Omega method - an engineering approach to life assessment; Transaction of ASME, Journal of Press Vessel Tech; 122: 3: 2000, p. 273-280.

[6] Viswanathan, Damage Mechanisms and Life Assessment of High Temperature Components; ASM International Ohio; 1989.

[7] Sim, R G, Reference Stress Concept in the Analysis of Structures during Creep; Int. J. of Mechanical Science; 12: 1970: p. 561-573.

[8] Sim, R G, PhD thesis; University of Cambridge; 1968.

[9] Zarrabi K. and Ng L, A Novel and Simple Approach for Predicting Creep Life Based on Tertiary Creep Behaviour; The ASME Pressure Vessels and Piping Conference; Vancouver, B.C., Canada; July 23-27; 2006 (in press).

[10] Ng L and Zarrabi K, Creep Life Prediction of 0.5\%Cr-0.5\%Mo-0.25\%V Thick Walled Cylinder using New Multiaxial Approach; Proceedings of the IMECE, ASME, Int. Mech. Eng. Cong. and Expo; Orlando Florida, USA; 2005.

[11] Hyde T H, Sun W, Becker A A, Williams J A, Creep continuum damage constitutive equations for the base, weld and heat-affected-zone materials of a service-aged 1/2Cr1/2Mo1/2V:21/4Cr1Mo multi-pass weld at $640{ }^{\circ} C$; J. Strain Anal.; 32:1997: p. 273-285. 
[12] Hyde T H, Becker A A and Xia L, Fatigue, Creep and Creep/Fatigue Behaviour of a Ti-Base Superalloy at $650{ }^{\circ} \mathrm{C}$; Proceedings of the third Int .Conf. Eng. Struct. Integ. Assessment; EMAS Ltd, West Midlands; 1996; p. 83-93.

[13] Hyde T H, Xia L and Becker A A, Prediction of Creep Failure in Aeroengine Materials under Multi-axial Stress States.; Int. J. Mech. Sci; 38: 4: 1996: p. 395-403.

[14] Kwon, O, Thomas C W and Knowles, D, Multiaxial stress rupture behaviour and stress-state sensitivity of creep damage distribution in Durhete 1055 and 2.25Cr1Mo steel; Int J of Pressure Vessels and Piping; 81: 6: 2004; June; p. 535-542.

[15] MSC/MARC, User Guide for Non-linear Creep Analysis; MSC.Software Corporation, USA; 2005. 